\title{
8
}

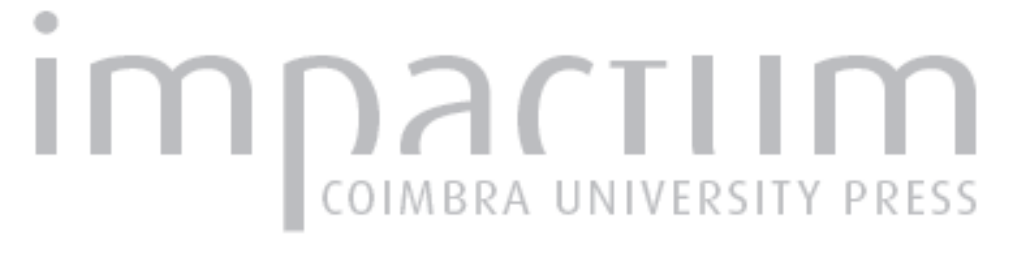

\section{Primeira anotação do curso de Arquitectura de Coimbra}

Autor(es): $\quad$ Costa, Alexandre Alves

Publicado por: Editorial do Departamento de Arquitetura

URL persistente:

URI:http://hdl.handle.net/10316.2/37315

DOI:

DOI:http://dx.doi.org/10.14195/1647-8681_3_3

Accessed : $\quad$ 26-Apr-2023 11:46:18

A navegação consulta e descarregamento dos títulos inseridos nas Bibliotecas Digitais UC Digitalis, UC Pombalina e UC Impactum, pressupõem a aceitação plena e sem reservas dos Termos e Condições de Uso destas Bibliotecas Digitais, disponíveis em https://digitalis.uc.pt/pt-pt/termos.

Conforme exposto nos referidos Termos e Condições de Uso, o descarregamento de títulos de acesso restrito requer uma licença válida de autorização devendo o utilizador aceder ao(s) documento(s) a partir de um endereço de IP da instituição detentora da supramencionada licença.

Ao utilizador é apenas permitido o descarregamento para uso pessoal, pelo que o emprego do(s) título(s) descarregado(s) para outro fim, designadamente comercial, carece de autorização do respetivo autor ou editor da obra.

Na medida em que todas as obras da UC Digitalis se encontram protegidas pelo Código do Direito de Autor e Direitos Conexos e demais legislação aplicável, toda a cópia, parcial ou total, deste documento, nos casos em que é legalmente admitida, deverá conter ou fazer-se acompanhar por este aviso.

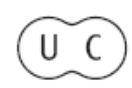




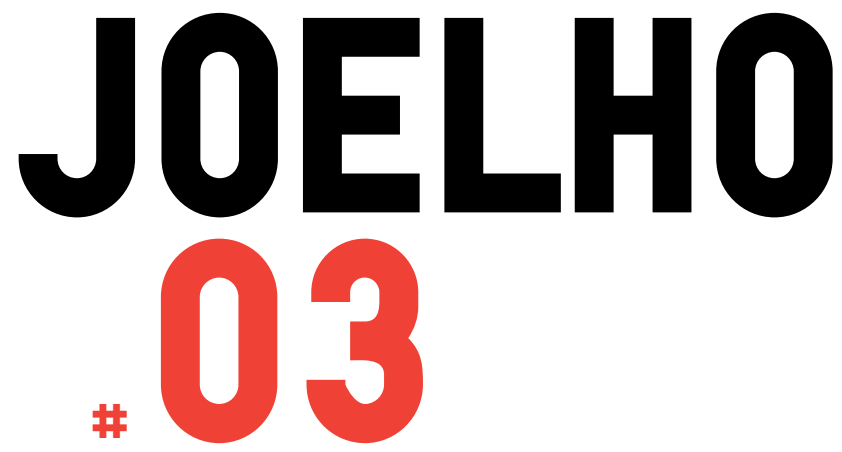

\section{VIAGEM-MEMÓRIAS: APRENDIZAGENS DE ARQUITECTURA}

Coordenação:

Alexandre Alves Costa

Domingos Tavares

Exposição Viagem

Exposição Memórias

Luis Mansilla

Alexandre Alves Costa

Domingos Tavares

SCA FoL DiNG
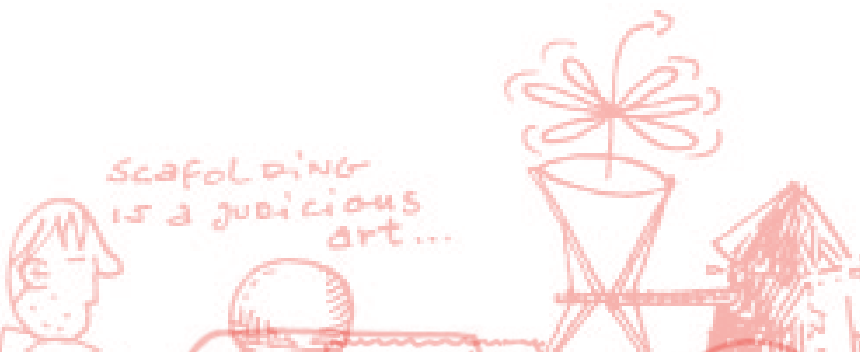

Jorge Figueira

José Miguel Rodrigues

José António Bandeirinha José Fernando Gonçalves

Paulo Providência

Gonçalo Canto Moniz Armando Rabaça

Patrícia Miguel

Bruno Gil

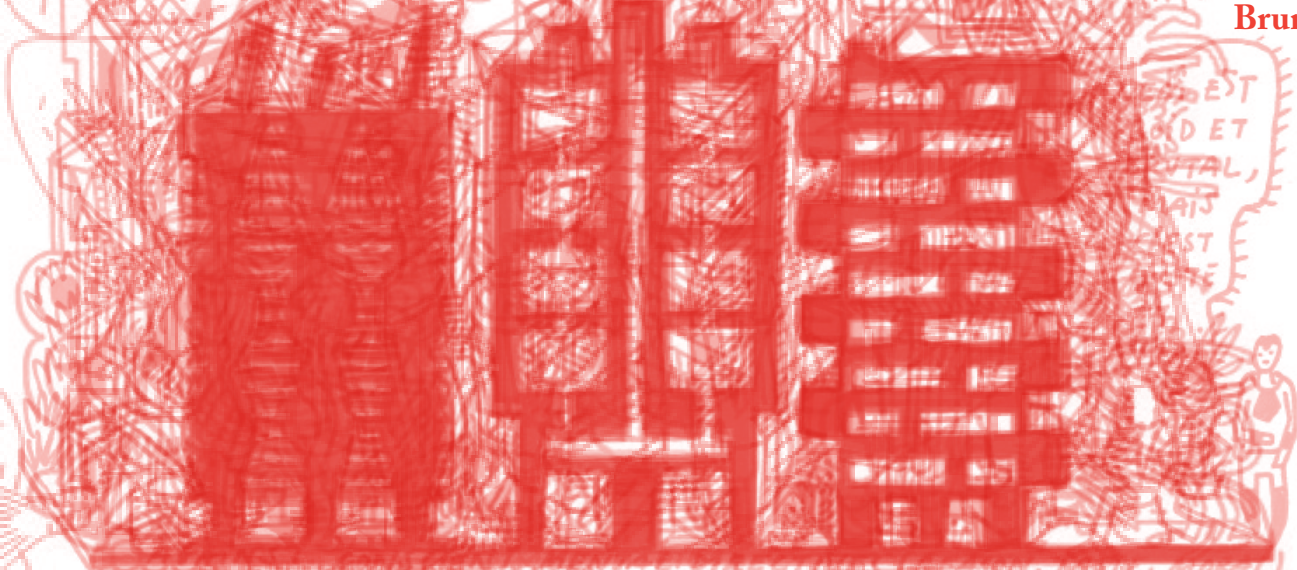

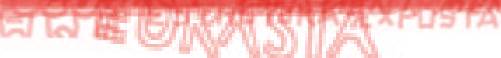




\section{Alexandre Alves Costa Primeira anotação do Curso de Ârquitectura de Coimbra}
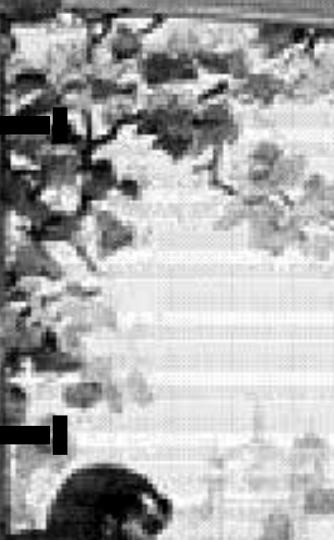

슨
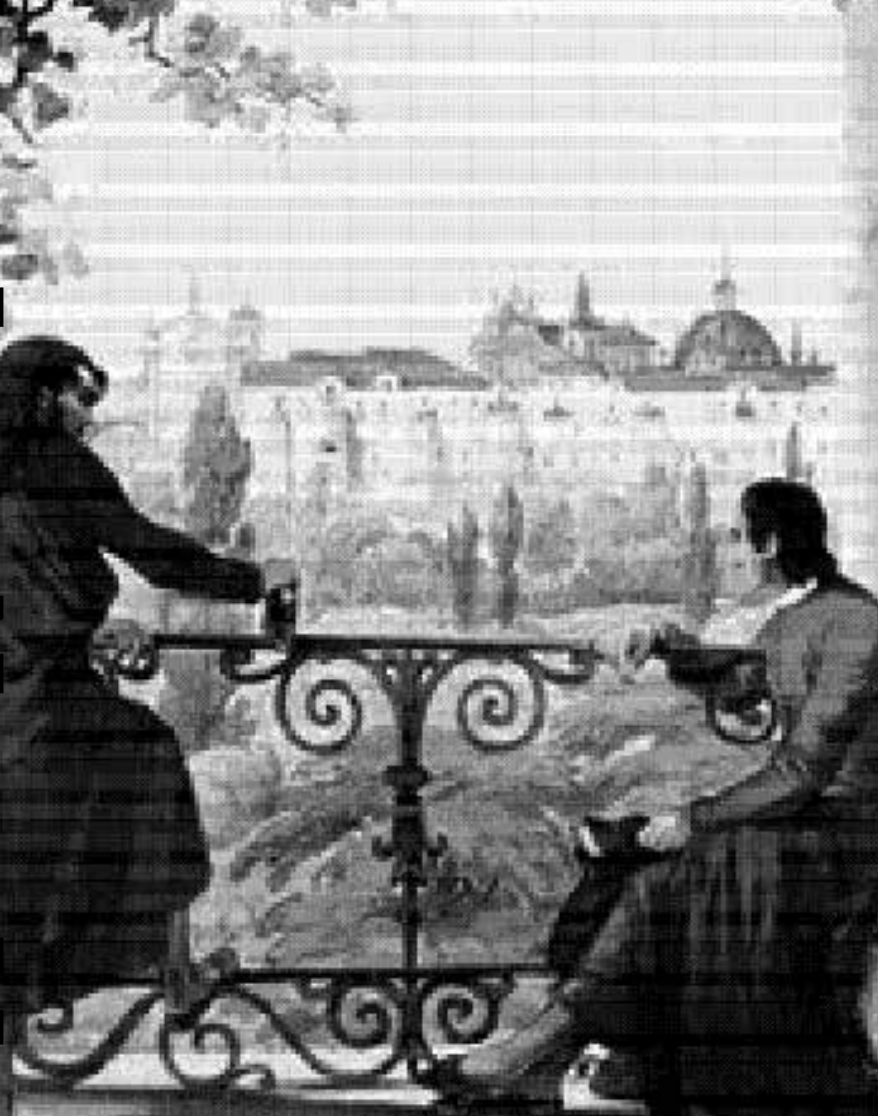
Tentarei seguir, de forma pouco precisa, algumas datas e alguns textos que correspondem a momentos significativos do novo Curso de Arquitectura em Coimbra, o primeiro que surge, em Portugal, por iniciativa da Universidade e não por integração das antigas Belas Artes, como aconteceu em Lisboa e no Porto. Corria o ano de 1988.

A Coimbra que eu, vindo de outros lados, amava, aparecia-me, nessa altura, perdida e arruinada, a desfazer-se sem razão e a refazer-se híbrida e desconexa. Assim a comparei a Portugal inteiro num texto para a Via Latina de Maio de 1991 (Costa, 1991, pp. 304-306), a mesma que trinta anos antes publicava a "Carta à jovem portuguesa", anunciando às queridas colegas a nova dignidade de assumirem a sua condição de iguais.

Como rude amador de antigos sonhos que sou, lembrei a cidade como a tinha vivido, cenário inesquecível de encontro, exaltação colectiva, capital das repúblicas da federação onde se construíam torres de assalto às muralhas das novas bastilhas, ao som das baladas do Zeca Afonso.

Anos depois, subi ao alto da enorme torre de Santa Cruz para espiar os movimentos de Almançor, e encontrei, presos à obra que produziram, os arquitectos que protagonizaram, em Coimbra, os avanços e recuos que, do manuelino ao chão, desenharam os caminhos de um Portugal venturoso nas rotas do mundo, humanista nas rotas da Europa já tridentina e daí neo-escolástico e inquisitorial, militar e expansionista ou, finalmente, nacionalista na austeridade da restauração.

Dirigi-me à rua da Sofia a tempo de ouvir o Horta Correia a explicar a consciência renascentista do valor demiúrgico do arquitecto que fez com que a arquitectura, para além de signo de poder, fosse, ao mesmo tempo, veículo e garante de transformações e reforma das instituições, tanto como das almas.

De facto, a partir da Reforma dos Estudos, contínuas e intensivas campanhas de obra construída, colocaram a questão não só da sua qualidade como, sobretudo, da sua eficácia. Aqui, não folgaram os mestres com habilidade ou mistério, acordados ao bom senso do gosto austero de um classicismo despido de qualquer ambiguidade pagã renascentista ou de tensão ou conflito maneirista.

Eram esses os tempos e eram duros, mais do que os de hoje, no Portugal democrático.

Salvou-os o saber do ofício, uns da construção, outros do desenho, outros da guerra, provavelmente tudo isto em cada um. A Coimbra que fizeram, seja arcaizante, conservadora ou de compromisso, é parte indissociável de uma das maneiras da arquitectura em Portugal. A Lisboa de Pombal é sua sucedânea, como lhe precede o processo de continuidade tipológica e construtiva do nosso românico e gótico.

Levantamos os olhos ao sol e vislumbramos o magnífico perfil do Colégio de Santo Agostinho, também conhecido pelo da Sapiência.

O espectáculo que se seguiu, desde a ruína da Torre de Santa Cruz ao Vale das Flores, e de regresso à Alta Universitária, fez-me sucumbir sob tristes presságios. 
Mas a arquitectura não entrara definitivamente no rol dos valores culturais a proteger e a empreender? Ou estará Coimbra submetida a algum insondável desígnio divino? Será que um non de Deus bloqueia o seu projecto?

Ouvi, não sei vinda de onde, uma gargalhada sinistra: mas que projecto?

Tentei responder, defender da desonra, da vergonha, a cidade, a universidade... Não respondi, mas pensei: talvez um Curso de Arquitectura, porque sendo o seu objecto central ensinar Projecto, pode calar os que se andam a rir de Coimbra. Depositava, assim, na arquitectura e na institucionalização do seu ensino alguma esperança regeneradora.

O Núcleo de Arquitectos da Região de Coimbra tinha-se adiantado, propondo a criação do novo curso, ideia acolhida favoravelmente pelo Reitor Prof. Rui Alarcão, pelo Presidente do Conselho Científico da Faculdade de Ciências e Tecnologia, Prof. Ribeiro Gomes, foi, até, apadrinhada pelo Presidente da Comissão de Coordenação da Região Centro. Alguém ou alguns, talvez o próprio Secretariado do Núcleo, ajudaram a construir o plano de estudos que, aprovado pelos órgãos de governo da Universidade, foi remetido ao Ministério da Educação.

Ainda em 1988 o próprio Núcleo organiza um encontro, largamente participado por especialistas, uns mais outros menos, para discutir qual deveria ser o perfil do arquitecto formado em Coimbra. Lembramos Silva Dias e Nuno Portas, mas o facto estava consumado e, quando se esperava que o Prof. Ribeiro Gomes prestasse alguns esclarecimentos sobre a concepção do novo curso, ele escusou-se em nome do respeito institucional a revelar mais pormenores para além do que já tinha dito: duração de cinco anos que compreenderão um tronco comum e três ramos de especialização no domínio da arquitectura e, ainda, que tinha sido decidido aproveitar algumas capacidades próprias da Faculdade. Muitos se ofereceram para colaborar, no futuro, com o novo curso, entre os quais o Prof. Fernando Távora, também presente na referida reunião.

A desilusão dos presentes foi grande, tendo dado origem a uma onda de suspeições que o discurso optimista de Teotónio Pereira, no encerramento do encontro, não conseguiu apagar. Existirão intenções menos nobres, nesta aparente generosidade por parte da FCTUC, em receber mais uma licenciatura, para além das dezasseis já ali ministradas? O Arq. Vasco Cunha mostrava-se satisfeito e foi o Núcleo de Arquitectos de Coimbra que veio a indicar, a pedido da Faculdade, o jovem licenciado João Mendes Ribeiro para integrar, como assistente, o novo corpo docente. Os primeiros alunos foram admitidos.

Os mais cépticos e, provavelmente, mais maldosos, sugeriam que se tratava, afinal, de tentar ampliar o mercado de trabalho para os engenheiros civis ameaçados, nessa época, de perderem alguns segmentos de mercado de trabalho a favor dos arquitectos, Com um bocadinho de desenho e algumas horas de projecto, os engenheiros ficavam, também, arquitectos! 
Em Junho de 1989 realizava-se, em Coimbra, o Congresso da Associação dos Arquitectos Portugueses que dedicou uma atenção particular ao problema do ensino da arquitectura.

Uma entrevista de Mendes Ribeiro, no Diário de Coimbra (1989, p.12), intitulada "Para que resulte: o Curso de Arquitectura de Coimbra tem de ser repensado", lançou o tema no Congresso, facto, ainda, dramatizado pela sua demissão, por discordância relativamente ao projecto pedagógico em curso.

Da Mesa dedicada ao ensino, e depois da intervenção de Manuel Taínha, tentei formular algumas propostas.

"Neste momento, em que para as Faculdades de Arquitectura se geram condições estáveis propiciadoras da livre experimentação pedagógica e didáctica e em que se consideram os centros de ensino como centros de investigação aplicada e como centros de prestação de serviços à comunidade, propomos, como primeiro ponto essencial, uma activa participação no reforço institucional de cada escola.

$A$ instituição é, de facto, o lugar privilegiado de encontro, meio onde a comunicação, na clareza dos códigos e hierarquia do relacionamento, é relativamente estável. $A$ instituição é inevitável e insubstituível, condição de subsistência e desejável, porque permite manter o que há de essencial em cada momento e resistir com saúde à maravilhosa dinâmica do provisório e do fortuito, do mundo absolutamente moderno em que nos incorporamos mais ou menos prazenteiramente. $E$ factor de ordem e estabilidade, de salvaguarda da memória, sem a qual não é possível pensar inovadoramente.

Em segundo lugar, as escolas deverão acordar, à maneira de Vitruvio, numa definição comum de arquitecto, como aquele que sabe. $E$ depois, montar o sistema necessário para, objectivamente, ensinar o que se considerar universal e perene para uma sólida formação académica, rigorosa, sistemática, igualitária. A instituição funciona aqui como reprodutora de códigos estáveis, garantia de continuidade, talvez até de uma certa opressão positiva.

Propomos, em terceiro lugar, que de uma reavaliação do território da arquitectura como problema na contemporaneidade, como processo de relação com o real construído, como reencontro da prática artística com o colectivo, se retirem argumentos gerais comuns que fundamentem os diferentes planos de estudo.

Em último lugar, se pensamos que quanto mais global é o problema mais local e mais multiplamente locais devem ser as soluções, cada escola deverá saber encontrar, a partir da sua própria tradição ou da interpretação que faz da sua história, das relações que deseja estabelecer e da consideração dos seus elementos constitutivos, as variantes experimentais ou de conviç̧ão particular que abram caminho à criação de novos e distintos valores, mesmo que no mesmo terreno do que se considera invariante: do desenho à construção, da teoria à história"

(Costa, 1989) 
Em síntese, um ensino da arquitectura assente em sólidas bases institucionais e pedagógicas que, a partir de uma avaliação rigorosa do território disciplinar, possa favorecer a ampliação das escolhas e a sua qualificação.

O Congresso aprovou uma moção dirigida ao Reitor da Universidade de Coimbra afirmando a autonomia disciplinar da arquitectura e defendendo a centralidade do projecto na sua aprendizagem. Entendida e aceite a pertinência do conteúdo da moção e a seu pedido, o Reitor da Universidade do Porto, Prof. Alberto Amaral, nomeou, para integrar a Comissão Instaladora do novo curso, Fernando Távora que, por sua vez se fez acompanhar dos dois companheiros que o tinham ajudado no processo de integração do Curso de Arquitectura na Universidade, dando forma à Faculdade de Arquitectura, Domingos Tavares e eu próprio. Juntamo-nos a outros colegas, não arquitectos, docentes na Universidade de Coimbra. A Comissão presidida pela Profa. Margarida Ramalho, do Departamento de Física, tomou posse em Dezembro de 19892. Seria injusto não referir a inteligência e a parcimónia daquela presidência que geriu o nosso grupo na consideração, inesperada nos tempos que correm, de que se tratava de matéria que lhe era estranha, respeitando sempre o grupo de arquitectos que considerava detentores do saber disciplinar que lhe faltava. A nossa integração na Universidade do Porto tinha-se realizado sem sequelas, ao contrário do que muitos temiam. As dificuldades que tivemos de ultrapassar estavam a ser vividas por todos, numa universidade que se estava a modernizar, nem sempre da melhor maneira. Por isso nunca nos sentimos sós, nem especialmente diminuídos, e a comunidade universitária reconheceu e respeitou a nossa história, a especificidade dos nossos métodos de ensino, a nossa peculiar forma de estar no mundo, a nossa autonomia e, até, a escolha que fizemos do arquitecto para construir as novas instalações, Álvaro Siza.

Foi com essa confiança e auto-estima que viajamos para Coimbra onde todos começamos a leccionar.

E perguntávamos, um pouco academicamente porque já tínhamos as respostas, mas que escola e para que arquitectura?

Sem tradição nem história no campo do ensino institucionalizado, deverá fazer suas a tradição e a história da cidade, por dentro da Universidade entendida como parte indissociável dela. O Curso de Arquitectura de Coimbra deverá seguir a cidade nos seus paradoxos constitutivos, não ser de Lisboa nem do Porto, sendo ambas as coisas. Ao contrário, será precário, periférico, provinciano. E pensava que não lhe fariam falta os pecados originais do academismo e/ou da modernidade, se souber colocar-se no lugar e no tempo da intervenção transformadora, a partir da realidade concreta e da capacidade de construção de uma visão própria sobre ela, criando uma estrutura compreensível no contexto das já existentes, realizando uma acção contrária às fórmulas do racionalismo utilitário que, ao quantificar, desqualifica.

E entramos, antecipadamente vitoriosos, na Faculdade de Ciências e Tecnologia onde fomos recebidos com alguns sorrisos que sempre 
interpretamos positivamente, embora, mais tarde, tivéssemos de reconhecer que alguns escondiam desconfiança ou até escárnio. É verdade que, desperdiçando recursos disponíveis, não fundamos uma escola com uma vertente tecnológica mais acentuada, como alguns desejaram. Lembro o discurso sobre essa matéria de Nuno Portas.

O nosso entendimento foi outro, talvez menos ingénuo, tendo ficado registado, nas suas linhas gerais, num conjunto de oito pontos programáticos "Learning From Coimbra, oito pontos estruturais para a construção de uma didáctica activa" que mais tarde publicamos na revista $N U$ (Costa, 2006, pp. 24-25).

Neste documento, escrito como um manifesto, em tom anos 70, faz-se apelo à autonomia disciplinar da arquitectura, ciclicamente atacada pelos tecnocratas e pelo desacreditado método científico que lhe pretende conferir, de fora, uma dignidade académica que, aparentemente, não possui. A retoma integral deste texto, correndo o risco de redundância, deve-se à sua premência na actual conjuntura de sobrevivência do Departamento de Arquitectura da FCTUC:

"1. Está suficientemente claro o território do arquitecto enquanto profissional de arquitectura - de fora os desvios que encaminhavam o exercício profissional para a dissolução na política ou nas ciências sociais. Outra coisa é o nosso dever de exercício da cidadania.

2. A arquitectura parte do real para o transformar. Projecto significa antecipação e implica, em primeiro lugar, uma referência ao futuro. Não há projecto sem futuro, nem é admissível uma referência projectual ao passado. Isso não impede, evidentemente, que a consideração do passado possa inserir-se na constituição do projecto; o que exclui é que esta possa representar uma sua condição de possibilidade, um seu constituinte essencial. Sendo o projecto uma previsão de possibilidade, ele é um dever ser e o acto de projectar um agir ético. $O$ sentido da arquitectura será a reconquista desta consciência.

3. Defendemos a artisticidade da arquitectura. Não é só no plano objectivo do conhecimento do real, mas também no plano da pura intuição subjectiva, que se elabora a síntese que constitui o projecto. Como forma de arte abrem-se-lhe perspectivas de compreensão do real em transformação, assumidamente diferentes da ciência, já nem essa com um processo metodológico puramente analítico. $O$ projecto tem início num a-priori, baseado na razão pura, sempre exposto à ameaça de dados que o desmintam - é o preço pago na procura de alternativas comprováveis. Os momentos de descrição e interpretação constituem a densidade da proposta.

4. A arquitectura não se inventa, avança sobre o real por pequenos passos, por pequenos distúrbios da realidade. Ela é, sempre, uma reavaliação da memória. Daí a importância da intuição, depois de aprender a ver a arquitectura e a sua relação com a vida. A história da arquitectura é, assim, para os arquitectos, matéria instrumental, não para fazer história, mas para lhe dar continuidade. Não se trata 
de criatividade sem regras. A estética e a metodologia artística não estão dedicadas idealisticamente à criação, à intuição livre de regras, à liberdade inventiva, mas serão, pelo contrário, uma estética e uma metodologia viradas para a definição e aplicação das leis formativas da arte. $A$ liberdade de espírito, na arte e na arquitectura, não é, de modo nenhum, isenta de vínculos, não coincide com um arbítrio rebelde a toda a lei.

5. Sabemos, como disse António Pedro, que a pintura flamenga não necessitou de pintar holandesas de socos para ser flamenga, o que não significa que a existência de formas ou conceitos identitários, mesmo que parciais ou locais, não possa ir a par da universalidade que tem qualquer obra de arte. Algumas escolas de arquitectura são exemplo disso. Não é, nem pode ser, uma ideia programática, construir uma identidade em Coimbra. Existirá ou não, se reforçarmos o nosso entendimento do mundo e do território onde agimos. Aparecerá se lhes identificarmos algum futuro que deva ser: a Coimbra e ao mundo.

6. A arquitectura não se ensina, aprende-se projectando. Não se ensinam linguagens codificadas mas aprendem-se nas escolas os instrumentos para o exercício projectual, sendo o desenho um instrumento privilegiado para a descrição, interpretação e construção da proposta transformadora. Trata-se de actualizar permanentemente os antigos saberes dos arquitectos que não andam, apesar das novas tecnologias, muito longe daqueles que foram sintetizados por Vitruvio há dois mil anos.

7. A arquitectura transforma a natureza ao serviço do homem. Ou o faz com bom senso e competência ou será o seu fim. O compromisso com o ambiente natural e construído é um compromisso para a sobrevivência.

8. O embaraço da esperança projectual urbanística pode lerse no rosto distorcido dos planos reguladores, mesmo quando não funcionaram como puros instrumentos de desregulação ou como projectos de legalização da desordem territorial. $O$ projectista, renunciando ao papel universal de produzir utopias consoladoras, deverá deslocar-se das impraticáveis mega-estruturas, para a interpretação micro-estrutural do espaço urbano e territorial que foi sempre construído por homogeneidade e quantidades artísticas acabadas. Sem o recurso a qualquer autoritarismo é, ainda, possível, com a participação dos cidadãos, numa espécie de iluminismo democrático, continuar a desenhar a cidade, sem aceitar passivamente a inevitabilidade da cidade genérica, agora perversamente transformada em objecto de fruição estética.

(Costa, 2006, pp. 24-25)

Nos primeiros anos de vigência da Comissão Instaladora, estabelecemos uma estratégia de qualificação e estabilização do novo curso. Fomos adaptando o plano de estudos às necessidades do ensino da arquitectura. 
Nunca quisemos ser um corpo estranho no seio da Universidade, mas antes um seu activo membro. Sabíamos da nossa Escola do Porto e sabíamos como a Universidade onde se integrou reconheceu as vantagens em acolher um discurso eclético e de contornos por vezes pouco evidentes a que não nos importámos, antes nos orgulhámos, que chamem artístico.

A acrescentar, a nossa convicção de que o projecto não se ensina, antes se aprende, projectando, dá aos nossos cursos um carácter de transmissão amigável de conhecimentos, sempre discutíveis, sem uma sobrecarga permanente de informação sistematizada e rigorosa que transforma o estudante em objecto e não em sujeito do ensino. Porque, como dizia em tempos Álvaro Siza, dosear em malha apertada e com parcimónia, o real inventado, as teorias e a sua história, os saberes técnicos e a criatividade artística, a informação de quem sabe da vida e das coisas, o desígnio transformador e o desejo de ser e afirmar a individualidade, é complexo e não consta dos manuais.

Sem conflitos geracionais, sem consensos apriorísticos, os cursos de arquitectura têm um carácter um pouco libertário, se os compararmos com as estruturas muito hierarquizadas e subtilmente autoritárias da universidade no seu conjunto.

Com o que sabíamos, actuamos em dois sentidos, o já referida qualificação do plano de estudos e a constituição de um corpo docente que nos iria ajudar a sedimentá-lo. O mais importante e o mais difícil era a área do projecto e, para isso, decidimos convidar docentes que, para além dos três que integravam a Comissão Instaladora, viessem a dar uma consistência real e simbólica ao esqueleto do curso. Vieram de Lisboa o Raúl Hestnes, o Manuel Taínha, o Vítor Figueiredo, o Gonçalo Byrne, o Manuel Graça Dias. Veio, também, do Brasil, passando por Vila Nova de Cerveira e pelo Instituto Superior Técnico, o Mário Kruger, primeiro e único, até hoje, Professor Catedrático do, entretanto chamado, Departamento de Arquitectura da FCTUC. Depois veio o Paulo Varela Gomes, o José Gigante, o José António Bandeirinha já lá estava. Vieram outros que seria ocioso nomear para as teorias, as histórias, a construção.

O corpo docente foi crescendo, conforme as necessidades de desenvolvimento do curso, aproveitando os melhores que, por diferentes razões, não tinham entrado no Porto ou em Lisboa. Todos vivemos com alguma ansiedade os seus processos de qualificação académica e a esperada entrada dos novos licenciados por Coimbra. Só assim, pensávamos, o processo de sedimentação do curso se tornaria irreversível e garantiria a sua desejável autonomia científica e pedagógica.

Os doutoramentos honoris causa de Fernando Távora, Álvaro Siza e, posteriormente, de Raúl Hestnes Ferreira, consagraram a respeitabilidade da arquitectura, assim reconhecida pela Universidade de Coimbra.

Creio que o ano de 1995 foi marcado por dois momentos muito significativos para esta nossa anotação ${ }^{3}$ o Concurso de Ideias para o Plano de Reconversão dos Espaços dos Colégios de S. Jerónimo, das Artes, Laboratório Químico e Área Envolvente e o I Encontro do Departamento, realizado em Tomar. 
Este Concurso para o qual foram convidados quatro professores de Projecto, Fernando Távora, Raúl Hestnes Ferreira, Gonçalo Byrne (que o ganhou) e eu próprio, foi sugerido pelo Departamento de Arquitectura e constituíu, nas palavras da Prof. Teresa Mendes (1997, p.11/12), então Vice-Reitora, "uma peça importante da política de valorização do património construído da Universidade... As propostas apresentadas a Concurso são, no seu conjunto, um contributo importante para a teoria da intervenção nos centros urbanos, para o conhecimento da Universidade e da área central de Coimbra."

Sobre este assunto, escreve Domingos Tavares (1997, p. 31/32) e aqui estão as suas palavras que condensam o que de mais importante apetece dizer, neste contexto:

"Desde que o Senado da Universidade aprovou o plano de distribuição dos edifícios existentes na área do antigo hospital pelos diferentes serviços, faculdades e departamentos, até às conclusões de orientação saídas deste concurso, sempre o Departamento de Arquitectura saiu beneficiado. É grande a importância que pode assumir a existência de uma escola de arquitectura na vivência de uma cidade e na formação da consciência cívica colectiva referida à arte urbana. Coimbra e a sua Universidade estarão a iniciar um processo de interrelação produtiva com a arquitectura enquanto escola e a construção da cidade enquanto arte. Então a entrega do antigo Colégio de S. Jerónimo à arquitectura (entrega desejada por todos, no nosso Departamento), pelo seu lugar proeminente na mais alta colina da alta, pela beleza fascinante do seu pequeno claustro quinhentista, pelo brilho da sua porta barroca, pelo esplendor da sua escada pombalina, pelo romantismo das suas orgânicas ampliações que a estrutura hospitalar lhe introduziu, assume-se como uma atitude simbólica que importa realçar e defender.

Qualquer das quatro propostas confirmou o Colégio de S. Jerónimo como a casa da arquitectura."

O Concurso e a publicação que se lhe seguiu, deram visibilidade interna e pública à competência própria dos arquitectos. Continuávamos a crescer e queríamos ficar na Alta.

Depois, e caminhando para as conclusões deste texto que é, afinal um repositório de documentos, as belas palavras, enigmáticas, não sei se pessimistas, mas certamente precoces, de Jorge Figueira (1997, p. 53), abrem um debate que não ocorreu ainda:

"Estes arquitectos são portadores de um projecto que procura ver e entender as coisas como se está mesmo a ver que elas já não são. Estes projectos pretendem fazer sentido, isto é, estar antes das coisas que já se perderam.

O projecto é aqui, em diversos graus e maneiras, um lugar humanista, tentando o despiste do arbítrio, da degeneração, da corrupção. 
Arquitectos sentados num lugar ideal: o lugar que lhes compete ancestralmente; alimentados dessa racionalidade que permite arduamente articular o inaliável, demolir o que foi somente construído, substituir o chão por paredes.

De forma distinta, a mesma procura de um lugar contemplado; sem ironia; perseguindo uma estratégia em tempo de tácticas; sem morbidez em relação ao peso morto do documento produzido; arquitectura: a mais exacta das artes defuntas..."

O I Encontro do Departamento de Arquitectura, realizado, meses antes, em Tomar, juntou, durante dois dias, todos os docentes do curso para uma reflexão colectiva sobre o ensino. Tinham-se formado os primeiros licenciados.

A Comissão Organizadora do Encontro ${ }^{4}$ escreveu, na altura:

"Para um curso que se tinha iniciado com tantos equívocos de que sofremos, ainda, algumas consequências, tratava-se de encerrar um complicado período de constituição e abrir um novo tempo de consolidação. O Encontro foi, antes de mais, uma declaração, sobretudo para si próprio, de reconhecimento de uma existência. Foi, depois, um confronto de ideias entre pessoas que, constituindo uma espécie de grupo natural, embora geograficamente disperso, queriam explicitar, comprovar ou construir o seu acordo que até aí tinham, apenas, como implícito. $E$ esse acordo, sedimentando uma ideia de escola para ensinar arquitectura, deveria constituir, não só uma espécie de carta de compromisso, como uma verdadeira demonstração de capacidade de gestão autónoma desse compromisso no âmbito de um projecto pedagógico.

$E$, por isso, se deu prioridade ao debate dos conteúdos e métodos de ensino com a consciência de que o verdadeiro acto fundacional do curso coincidiria com o estabelecimento de uma estratégia que nos fortalecesse como corpo e permitisse a manifestação da diferença como elemento de estímulo para o desenrolar do debate interno.

A divisão temática por áreas do conhecimento foi uma facilidade assumida com a consciência de que não se pode separar o que deverá ser convergente. Discutiu-se o projecto e o desenho, a construção e a história, mas a síntese que dará existência objectiva e especificidade à Escola de Coimbra só existirá, de facto, com obra no terreno e no seu retorno crítico ao interior.

Passado algum tempo vemos que fizemos o mais belo e o mais fácil.

Reconhecemo-nos nos discursos uns dos outros, confirmamos o que já sabíamos, gravamos as nossas imagens e as nossas palavras para uma posteridade que só nos perdoará o gosto que tivemos se lhe demonstrarmos capacidades para, determinado o que a escola quer ser, lhe darmos forma objectiva.

Do esboceto à obra, quanto trabalho medeia, e por tratar ficaram alguns aspectos que se tem revelado estruturais: das instalações, às questões administrativas, do desenvolvimento da investigação ao 
currículo, do crescimento e qualificação do corpo docente, ao empenho

dos estudantes, dos mecanismos da participação aos da gestão. Tudo

na evidência de que a conquista do reconhecimento da autonomia

disciplinar da arquitectura, que faltava em Coimbra, acarreta a

responsabilidade de conquistar uma escola com total autonomia

financeira, administrativa e científica. Trata-se, simplesmente, de

desenvolver o projecto. Certamente noutros Encontros de Tomar"

(Encontro de Tomar, 1997, p. 7)

Realizaram-se outros. O corpo docente está renovado com uma maioria de doutores e os outros em processo de doutoramento. Mas aquela escola ainda está por conquistar e os tempos são outros.

A reflexão deverá alargar-se. Já não se esperam respostas para as antiquíssimas perguntas dos anos oitenta do século passado, sobre que escola, para que arquitectura, em Coimbra.

Todos teremos de reflectir sobre que escola para que arquitectura no mundo, nesta época de mudança de paradigma para um incerto futuro. $O$ terreno é vago e nem esse, nem sequer as nossas conquistas de oitenta, são nossos.

Não conseguiremos dar dois passos em frente sem, antes, recuar um? Reconheci, não sei vinda de onde, uma gargalhada sinistra.

Folheio o tratado de Vitruvio, oferecido pelo Arquitecto Fernando Távora, e sinto saudades de ambos.

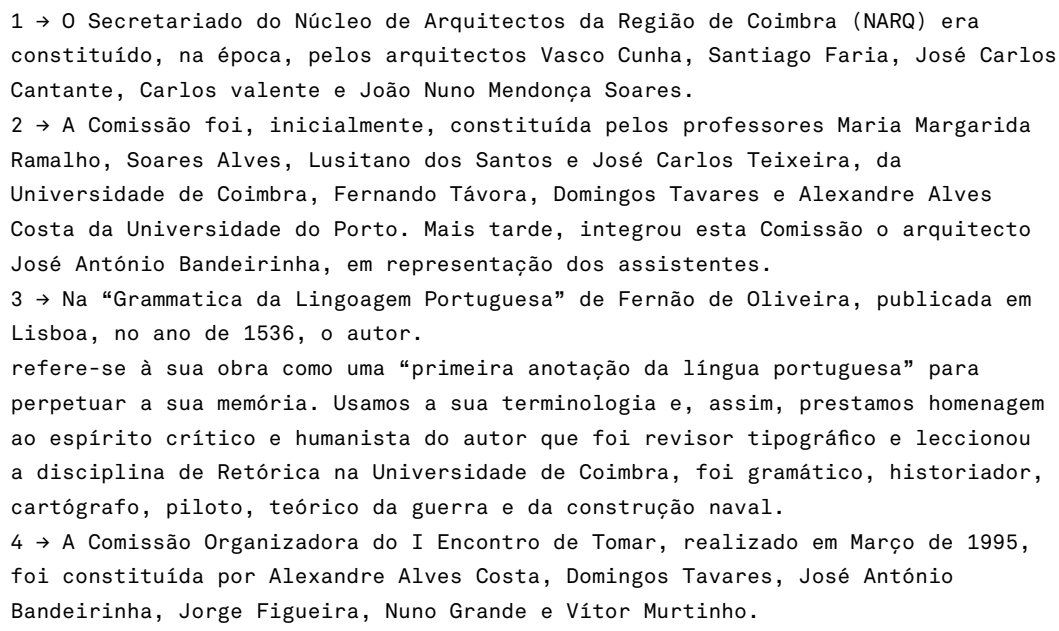

Bibliografia

Costa, A. A. (1989). Texto apresentado no

5. ${ }^{\circ}$ Congresso da AAP, Seç̧ão 2, Subtema 3,

"O Processo Formativo".

-

Costa, A. A. (1991). Coimbra é Portugal Inteiro. Via Latina, 3, pp. 304-306.

-

Costa, A. A. (1989). Jornal dos arquitectos.

Costa, A. A. (2006). Learning From Coimbra, oito pontos estruturais para a construção de uma didáctica activa. NU identidade, 26, p. 24/25.
Diário de Coimbra (1989-06-15). p. 12.

$$
\text { - }
$$

Mendes, T. (1997). Concurso de Ideias... In A Alta de Volta. Coimbra: e|d|arq.

-

Encontro de Tomar. I Encontro sobre o ensino da Arquitectura na Universidade de Coimbra (1997). Coimbra, e|d|arq.

Domingos T. (1997). Um plano para a Alta do fim do século XX. In A Alta de Volta (pp. 31-32). Coimbra: e|d|arq.
Figueira, J. (1997). A próxima Alta. In A Alta de Volta (pp. 53). Coimbra: e|d|arq.

Mendes, T., \& Cortesão, C. (1997). Concurso de Ideias... In A Alta de Volta (pp. 11-13). Coimbra: e|d|arq. 